\title{
Evaluate the Severity of Complications for Percutaneous Nephrolithotomy and Open Surgery for Large Renal Stone
}

\author{
Hanan Ali Ahmed Abdelmowla, Rasha Ali Ahmed Abdelmowla, Attyiat Hassan Hussein, Ahmed Abdelhamid \\ Shahat \& Medhat Ahmed Abdalla
}

Demonstrator in Adult Nursing Department (Medical-Surgical), Faculty of Nursing, Assiut University, Egypt. Lecturer in Adult Nursing Department (Medical-Surgical), Faculty of Nursing, Assiut University, Egypt.

Lecturer in Adult Nursing Department (Medical-Surgical), Faculty of Nursing, Assiut University, Egypt.

Lecturer of Urology, Faculty of Medicine, Assiut University, Egypt.

Professor of Urology, Faculty of Medicine, Assiut University, Egypt.

\begin{abstract}
Urinary stone disease is the third most common problem in urology clinics after urinary tract infections and prostate disease. Objectives: evaluate severity of complications of percutaneous nephrolithotomy (PNL) and open surgery for large renal stones. Patients: 150 adult patients with renal stones more than $2 \mathrm{~cm}$ were distributed into two equal groups. Group A had PNL and group B had open surgery. Design: Quasi- experimental research design. Setting Assiut Urology and Nephrology Hospital. Tools: (1) Patient assessment sheet and (2) Clavien-Dindo grading system for classification of surgical complications. Results: No significant relation between the both group regarding complications, stone clearance and need for blood transfusion, while mean hospital stays showed significant relation between the both group. As a group (A) stay only 3.7 \pm 1.2 days in hospital after operation while group B stay longer time, $6.1 \pm 0.53$ days after operation.Conclusions: Open renal surgery for large sized stones still has its role in selected cases with stone clearance and complications rates comparable to PNL. Recommendation: The choice between PNL and open surgery for renal stones should be individualized for each patient.
\end{abstract}

Keywords: Renal Stone, Percutaneous Nephrolithotomy \& Open Renal Stone Surgery.

\section{Introduction}

Urinary stone disease is the third most common problem in urology clinics after urinary tract infections and prostate disease (Rafiei et al., 2014). The main goal of surgical intervention for renal stones is complete stone clearance. In the last decades, percutaneous nephrolithotomy (PNL) has replaced open renal stone surgery (ORSS) and became the first line for management of complex or large renal stones. However, in our localities, ORSS still has a larger role due to social and economical factors (Wang et al., 2014).

Complications of management of renal stones differ from one method to another. Despite the significant advancements in the surgical management of urinary stones, morbidity, and even mortality are still being reported. Deaths still occur after surgery, particularly in the elderly population as their immunity is lower and there could be a delay in diagnosis due to lack of classical symptoms (Krambeck \& Lieske 2011).

Some bleeding is normal in/or around the kidney after PNL, if bleeding is significant enough there is a need for blood transfusion. If bleeding does not stop it can be necessary to have an angiogram to block the blood vessel that is bleed. In the rare cases when bleeding does not stop it can be necessary to remove the kidney. Other complication should be treated such as infection because some stones have bacteria trapped within them. The patient receives antibiotics routinely to prevent infection after the operation (Lee et al., 2013, Lu et al., 2010, Mousavi-Bahar, Mehrabi \& Moslemi 2011).

Injury to the lung cavity in PNL: there is a small chance of pockets of air or fluids forming around a lung if the needle is inserted toward the upper portion of the kidney. These pockets are treated with a chest tube, which allows the fluid to drain from around the lung (Bjurlin et al., 2012) and retained fragments; sometimes not all stones are removed and these may need further treatment as SWL or second look PNL (Rosette et al., 2011, Shin et al., 2011).

The risks of ORSS include severe bleeding (Occasionally a patient may need to have a blood transfusion), infection and incision hernia where the cut was made for surgery(Matlaga \& Lingeman 2011). Risks linked with anesthesia include- Very common side effects such as: Feeling sick and vomiting after surgery, sore throat, dizziness, blurred vision, headache, itching, aches, pain, and backache, pain during injection of drugs, bruising and soreness and confusion. Uncommon side effects and complications such as Chest infection, muscle pains, and slow breathing. Rare complications such as Serious allergy to drugs, nerve damage, and death. 
(Akman et al., 2012, Bozkurt et al., 2011, Turk et al., 2016).

Assessments of surgical complication remained limited by the lack of consensus on how to define postoperative complications and how to grade them. The modified Clavien-Dindo system has been proposed for this purpose. Since that, it has been used widely in the hospital setting to assess the complications of a broad range of surgeries including surgery for renal stones. In this study, we used the modified Clavien-Dindo system to asses and compare complications of PNL and ORSS removal regarding rate and type of complications (Braticevici et al., 2014).

All patients with PNL and ORSS for removal of renal stone are needed for preoperative and postoperative care by the nurse. Enhance communication with patients; co-operation for nurses should take the initiative in communicating with patients, give support and encouragement to ensure the successful completion of interventional procedures. Seriously listen to complaints of patients to detect complications in time (Tang et al., 2011).

Nurses should pay attention to patient's counseling so that patients and their families understand the surgical principles and possible postoperative complications. A comprehensive assessment should be done on patients' admission to identify health problems such as hypertension, coronary heart disease, diabetes, and hepatitis. Acute urinary tract infection should be controlled before surgery (Liu et al., 2013).

Close observation and standard care for improving the success rate of intervention and prevention of complications is important. Preoperative assessment should include urine examination, kidney function, blood tests, chest radiograph, electrocardiogram, blood coagulation time and skin preparation (Antonelli \& Pearle 2013).

Nurse has a very important role in detecting early post-operative complications and preventing further complications. Nurse should emphasize to the patient the importance of reporting symptoms immediately. Postoperative care should include the following measures: close monitoring of vital signs especially when patient complains of shortness of breath and chest tightness, there is possibility of pneumothorax, close observation of urine output and color changes; also amount of urine should be measure and recorded to maintain patency to the drainage catheter. Monitoring for postoperative complications should include careful observation of wound, dressing, drainage tube as well as preventing infection (Liu Yiwen \& Jiping 2011).

Observation and care of postoperative bleeding occur for patients with a varying degree of postoperative bleeding. The nurse should be alert to changes in vital signs and observe color of drainage, nature, and quantity to judge and make a record. Discharge guidance issued to the patients about the importance of follow-up to prevent many postoperative complications (Seitz et al., 2012).

\section{Significance of the study}

There are various methods of intervention for managing renal stones; ORSS and PNL. However, it should be noted that these interventions often lead to life-threatening complications, even when performed by experienced surgeons. Complications should be evaluated and detected early to eliminate their effects on patients' health and to evaluate the best surgical methods. Nurses main role are to assess patients undergoing surgical intervention pre and post operatively. Based on patient condition and data collected by the nurse-physician will identify the best surgical methods that should be followed, also will detect early possible complications.

Aim of the study

To evaluate the severity of complications for percutaneous nephrolithotomy and open renal stone surgery for large renal stone

\section{Research hypothesis}

To fulfill the aim of the study, the following hypothesis was formulated:

The severity of complications in ORSS will be more than in PNL.

\section{Methodology}

Research design

Quasi- experimental research design was utilized in this study.

\section{Technical design}

Setting

This study was conducted at Assiut Urology and Nephrology Hospital.

Subjects

A purposive sample size of 150 patients was determined. They were suffering from renal stones with stone burden more than $2 \mathrm{~cm}$, of both genders between 18 and 65 years old. The stones were evaluated using renal ultrasonography, X-ray and Multislice non-contrast computed tomography. The patients were distributed into two equal groups; each contains 75 patients. Group A had PNL and group B had open surgery for renal stone(s) removal according to the physician.

Exclusion criteria

- Bleeding tendencies.

- Untreated active urinary tract infection.

- Pregnancy.

Study tools

Tool I: Patient assessment sheet 
It was developed by the researcher after validation, to assess the patients conditions and problems. This tool consisted of three parts:

Part I: It is used to assess socio-demographic characteristics of the patient's e.g. age, gender, level of education, occupation and marital status.

Part II: Medical data:

It consists of a health history; it is used to assess the following:

- Medical history: - It includes present and past history; medical diagnosis, clinical manifestation, criteria of disease [location of the stone, stone number, stone size and previous stone], surgical management, postoperative medical treatment, chronic illness, previous renal stone and presence of stent.

- Laboratory investigation \& diagnostic procedures: Estimated glomerular filtration rate was calculated using serum creatinine by the Modification of Diet in Renal Disease (MDRD) formula (Levey et al., 2007).

- Hydronephrosis was graded into mild, moderate and severe according to sonographic findings using Society of Fetal Ultrasound (Keays et al. 2008).

Grade 0

- No dilatation, calyceal walls are apposed to each other

Grade 1: (mild)

- Dilatation of the renal pelvis without dilatation of the calyces (can also occur in the extrarenal pelvis) or with dilatation of the renal pelvis (mild) and calyces (pelvicalyceal pattern is retained).

- No parenchymal atrophy

Grade 2: (moderate)

- Moderate dilatation of the renal pelvis and calyces

- Blunting of forces and flattening of papillae

- Mild cortical thinning may be seen

Grade 3 :(severe)

- Gross dilatation of the renal pelvis and calyces, which appear ballooned

- Loss of borders between the renal pelvis and calyces

- Renal atrophy was seen as cortical thinning

WHO performance status scale (PS): Designed by (Oken et al. 1982). The performance status describes the status of symptoms and functions with respect to ambulatory status and need for care, performance status stratified into:-

- Grade 0: Normal activity

- Grade 1: Restricted in physically strenuous activity but ambulatory and able to carry out work of a light or sedentary nature.

- Grade 2: Less than $50 \%$ of daytime in bed.

- Grade 3: More than $50 \%$ of daytime in bed.
- Grade 4: Completely disabled.

- Grade 5: Dead

Part III: Operative \& post operative data

It includes method of stone treatment (PNL and ORSS), clearance and residual stone, length of hospital stay, stent, renal function test, performance status and auxiliary maneuvers assessed after 3 months from data of operation.

Auxiliary maneuver define as

- Conversion to other modality of treatment.

- Need for second operation (in case of PNL second look within seven days considered as complementary procedure and double $\mathrm{J}$ stent removal.

Tool (2): Clavien-Dindo grading system for the classification of surgical complications.: Developed in 1992 by Clavien et al. It was reevaluated and modified in 2004 use to classify complications based on life-threatening conditions, interventions required, and disability complications were stratified into five grades (Dindo et al. 2004).

- Grade 1: Any deviation from the normal postoperative course without need for pharmacologic treatment or surgical, endoscopic, and radiologic interventions, allowed therapeutic regimens as antiemetic, antipyretics, analgesics, diuretics, electrolytes, and physiotherapy. This grade also includes wound infections.

- Grade 2: Complications requiring pharmacologic treatment with drugs other than such allowed for grade 1 complication. Blood transfusions and total parenteral nutrition are also included.

- Grade 3: Complications requiring surgical, endoscopic, or radiologic intervention

- Grade 3a: Intervention not under general anesthesia

- Grade3b: Intervention under general anesthesia

- Grade 4: Life-threatening complications (including central nervous system Complications) requiring intensive care unit stay.

- Grade 4a: Single organ dysfunction (including dialysis)

- Grade 4b: Multiorgan dysfunction.

- Grade 5: Death of the patient.

Operational design

Procedure

The study was carried out in 3 phases

Phase (1): preparatory phase

In which an official permission to proceed with the proposed study was obtained. Preparation of the data collection tools was carried out by the researcher after extensive literature review (nursing and medical textbooks, journals, internet resources) at this phase. 


\section{Content validity}

The content and validity were done by five expertise from the medical staff of urology and medicalsurgical nursing staff. Two expertise from medicalsurgical nursing staff and three expertise from urology staff who reviewed the tools and the nursing educational program for clarity, relevance, comprehensiveness, understanding, applicability and easiness for administration. The content is valid and reliable.

Reliability was assessed by correlation coefficient with $>0.8$ considered strong.

\section{Pilot study}

It was conducted on $10 \%$ of the sample in a selected setting for testing clarity and applicability of the study tools. The purpose of the pilot study was to detect any particular problem in the statements clarity, feasibility, and applicability of the tool. The data obtained from the pilot study were analyzed; no change was done in the assessment sheet, so the $10 \%$ of subjects selected for the pilot study were included in the main study subjects.

Phase (2): Implementation phase: At initial interview, the researcher introduces herself to initiate communication, explain the nature and purpose of the study. Patients were visited daily during hospitalization to assess patients` conditions before and after renal stone management by ORSS and PNL.

- Patients meeting the criteria for possible inclusion were approached by the researcher.

- Patient's agreement for voluntary participation was obtained after explaining the purpose and nature of the study.

- After taking the patient agreement for participating in the study, the data about patients' as the current medical condition was collected through tool I.

- Patients' complications after stone management were assessed using tool II.

- Confidentiality and anonymity of the patients' data were assured and collected using the study tools I and II.

- As well as, the researcher emphasize the importance of follow-up visit to observe any complications.

- Patient's names were coded for data entry so that their names could not be identified.

\section{Phase (3): Follow-up phase}

During follow-up phase 5 patients after PNL and 7 patients after ORSS were missed so they were excluded from the study and other patients were selected in the study according to inclusion criteria.

- As regard Clavien-Dindo grading system, complications were assessed immediately after treatment (ORSS, PNL) and through a period of 6 weeks after operation.
- Stone clearance was assessed 1 and 3 months after operation using ultrasonography, X-ray and Multislice non-contrast computed tomography was done in selected cases. It was defined as no residual stone(s) more than $4 \mathrm{~mm}$.

\section{Ethical considerations}

- Research proposal approved from Ethical Committee in the faculty of nursing.

- The study followed common ethical principles in clinical research.

- There is no risk for patients during application of research.

- Written consent obtained from patients or family that they are willing to participate in study, after explaining the nature and purpose the study.

- Confidentiality and anonymity assured.

- Patients have the right to refuse to participate and/or withdraw from the study without any rational at any time.

- Patients' privacy considered during collection of data.

\section{Statistical analysis}

Statistical analysis was done using IBM SPSS 19. Quantitative data was analyzed using student t-test, while qualitative data was analyzed using Pearson chi-square test and Fisher-exact test.

\section{Limitation of the study}

The main limitation of this study is being nonrandomized. The used technique was chosen according to preference of surgeon and was individualized for each patient. This may be the reason behind the lack of difference in complications rates in both groups. 


\section{Results}

Table (1): Socio-demographic characteristics of patients included in the study with renal stones treated by PNL and ORSS.

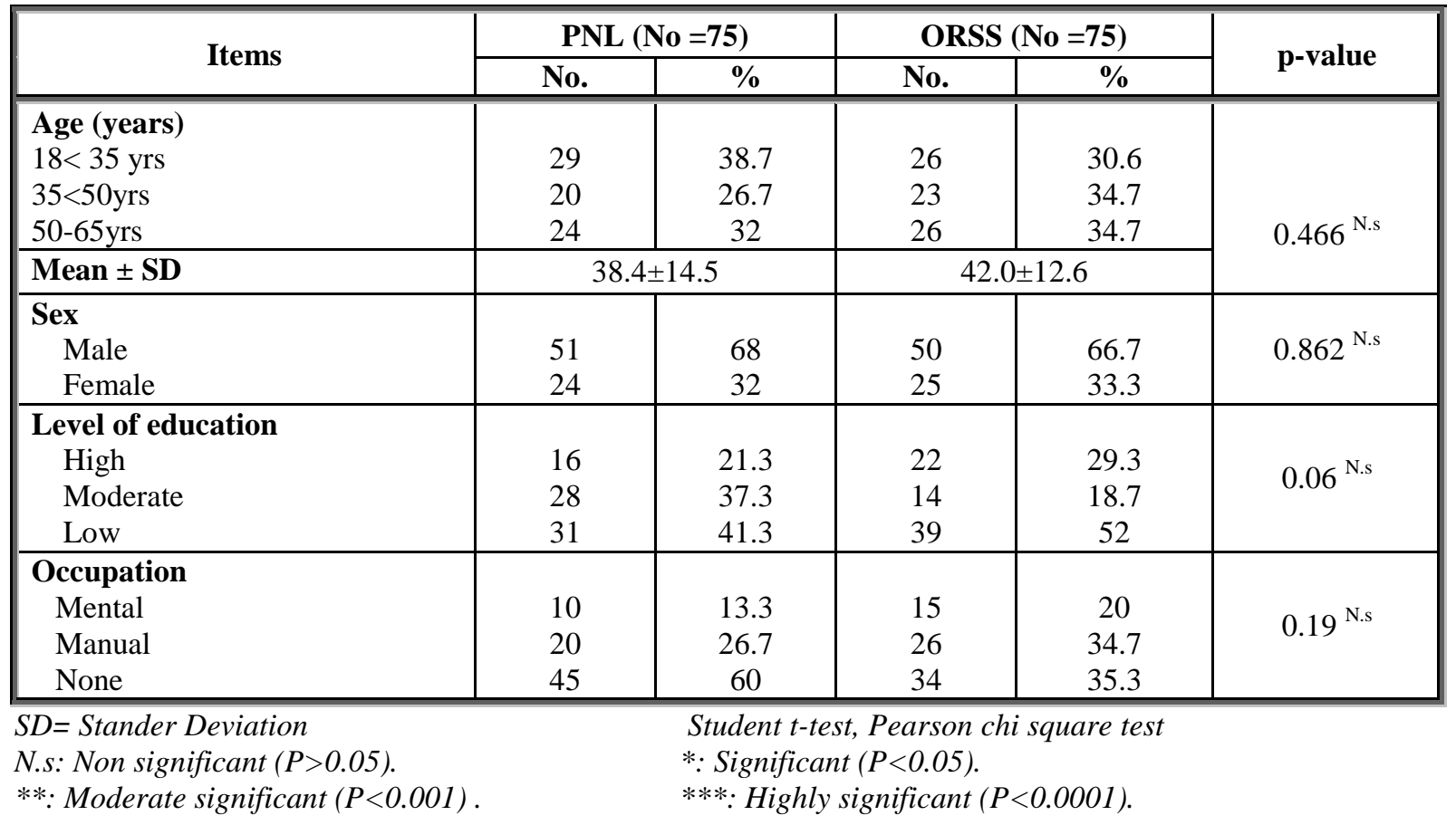

Table (2): Medical co-morbidities of among the study groups (PNL and ORSS).

\begin{tabular}{|l|c|c|c|c|c|}
\hline \multirow{2}{*}{ Medical co morbidities } & \multicolumn{2}{|c|}{ PNL(No=75) } & \multicolumn{2}{c|}{ ORSS(No=75) } & \multirow{2}{*}{ P-value } \\
\cline { 2 - 6 } & No & $\%$ & No & \% & \\
\hline \hline $\begin{array}{l}\text { Hepatic disease } \\
\text { Hepatitis B }\end{array}$ & 1 & 1.3 & 1 & 1.3 & $1.00^{\text {N.s }}$ \\
\hline Diabetic & 10 & 13.3 & 10 & 13.3 & $1.00^{\text {N.s }}$ \\
\hline Hypertension & 9 & 12 & 13 & 17.3 & $0.319^{\text {N.s }}$ \\
\hline $\begin{array}{l}\text { Heart disease } \\
\text { Ischemic heart disease }\end{array}$ & 1 & 1.3 & - & & $0.359^{\text {N.s }}$ \\
\hline P-value & \multicolumn{3}{|c|}{0.690} & - & \\
\hline
\end{tabular}

Pearson chi-square test.

Table (3): Clinical presentation of the study groups regarding renal stones before treatment by PNL and ORSS.

\begin{tabular}{|c|c|c|c|c|c|}
\hline \multirow[t]{2}{*}{ Clinical presentation } & \multicolumn{2}{|c|}{$\begin{array}{c}\text { PNL } \\
(\text { No }=75)\end{array}$} & \multicolumn{2}{|c|}{$\begin{array}{c}\text { ORSS } \\
(\mathrm{No}=75)\end{array}$} & \multirow[t]{2}{*}{ P-value } \\
\hline & No & $\%$ & No & $\%$ & \\
\hline Pain & 71 & 94.7 & 73 & 97.3 & $0.471^{\mathrm{N} . \mathrm{s}}$ \\
\hline Hematuria & 30 & 40 & 29 & 38.7 & $0.868^{\mathrm{N} . \mathrm{s}}$ \\
\hline $\begin{array}{l}\text { Infection } \\
\text { A febrile urinary tract infection (UTI) } \\
\text { Febrile UTI }\end{array}$ & $\begin{array}{c}11 \\
6 \\
\end{array}$ & $\begin{array}{c}14.7 \\
8 \\
\end{array}$ & $\begin{array}{l}9 \\
8 \\
\end{array}$ & $\begin{array}{c}12 \\
10.7 \\
\end{array}$ & $1.00^{\mathrm{N} . \mathrm{s}}$ \\
\hline Lower urinary tract symptoms & 26 & 34.7 & 25 & 33.3 & $0.813^{\mathrm{N.s}}$ \\
\hline Gastrointestinal symptoms & 41 & 54.7 & 40 & 53.3 & $0.864^{\mathrm{N} . \mathrm{s}}$ \\
\hline P-value & \multicolumn{5}{|l|}{$0.405^{\mathrm{N} . \mathrm{s}}$} \\
\hline
\end{tabular}

Pearson chi-square test. 
Table (4): Comparison between all groups of patients before treatment and stone criteria.

\begin{tabular}{|l|c|c|c|c|c|}
\hline \multirow{2}{*}{ Stone criteria } & \multicolumn{2}{c|}{$\begin{array}{c}\text { PNL } \\
\text { (No=75) }\end{array}$} & \multicolumn{2}{c|}{ ORSS } \\
(No=75)
\end{tabular}

Student t-test, Pearson chi square test

Table (5): Comparison between the study groups regarding patients` conditions before treatment.

\begin{tabular}{|c|c|c|c|c|c|}
\hline \multirow{2}{*}{ Patients`conditions } & \multicolumn{2}{|c|}{$\begin{array}{c}\text { PNL } \\
(\text { No }=75)\end{array}$} & \multicolumn{2}{|c|}{$\begin{array}{c}\text { ORSS } \\
(\text { No }=75)\end{array}$} & \multirow[t]{2}{*}{ P-value } \\
\hline & No. & $\%$ & No. & $\%$ & \\
\hline Solitary kidney & 8 & 10.7 & 4 & 5.3 & $0.229^{\mathrm{N} . \mathrm{s}}$ \\
\hline $\begin{array}{l}\text { Hydronephrosis } \\
\text { Mild } \\
\text { Moderated } \\
\text { Severe } \\
\end{array}$ & $\begin{array}{c}37 \\
11 \\
1 \\
\end{array}$ & $\begin{array}{c}49.3 \\
14.7 \\
1.3 \\
\end{array}$ & $\begin{array}{c}34 \\
20 \\
1\end{array}$ & $\begin{array}{c}45.3 \\
26.7 \\
1.3 \\
\end{array}$ & $0.212^{\mathrm{N} . \mathrm{s}}$ \\
\hline $\begin{array}{l}\text { Estimated Glomerular filtration rate } \\
>60 \mathrm{~mL} / \mathrm{min} / 1.73 \mathrm{~m}^{2} \\
<60 \mathrm{~mL} / \mathrm{min} / 1.73 \mathrm{~m}^{2}\end{array}$ & $\begin{array}{l}61 \\
14\end{array}$ & $\begin{array}{l}81.3 \\
18.7\end{array}$ & $\begin{array}{l}60 \\
15\end{array}$ & $\begin{array}{l}80 \\
20\end{array}$ & $0.836^{\text {N.s }}$ \\
\hline Medical co morbidity & 15 & 20 & 17 & 22.7 & $0.690^{\mathrm{N} . \mathrm{s}}$ \\
\hline Preoperative double J stent & 24 & 32 & 16 & 21.3 & $0.140^{\mathrm{N} . \mathrm{s}}$ \\
\hline $\begin{array}{l}\text { Preoperative performance status: } \\
\text { I: Normal activity } \\
\text { II: Restricted in physically strenuous activity } \\
\text { III: Less than } 50 \% \text { of daytime in bed } \\
\text { IV: More than } 50 \% \text { of daytime in bed } \\
\end{array}$ & $\begin{array}{r}25 \\
45 \\
3 \\
2 \\
\end{array}$ & $\begin{array}{c}33.3 \\
56 \\
4 \\
2.7 \\
\end{array}$ & $\begin{array}{c}18 \\
55 \\
1 \\
1 \\
\end{array}$ & $\begin{array}{c}24 \\
73.3 \\
1.3 \\
1.3 \\
\end{array}$ & $0.324^{\text {N.s }}$ \\
\hline
\end{tabular}

Pearson chi-square test.

Table (6): Comparison between the both study groups (after surgery and after 3 months follow-up) regarding stone clearance and postoperative hospital stay.

\begin{tabular}{|c|c|c|c|c|c|}
\hline \multirow[t]{2}{*}{ Items } & \multicolumn{2}{|c|}{$\begin{array}{c}\text { PNL } \\
(\text { No }=75)\end{array}$} & \multicolumn{2}{|c|}{$\begin{array}{c}\text { ORSS } \\
(\text { No }=75) \\
\end{array}$} & \multirow[t]{2}{*}{ P-value } \\
\hline & No & $\%$ & No & $\%$ & \\
\hline \multirow{2}{*}{$\begin{array}{l}\text { Stone clearance } \\
\text { Immediately postoperative } \\
\text { Three months after surgery }\end{array}$} & & & & & \multirow[b]{2}{*}{$0.002^{*}$} \\
\hline & $\begin{array}{l}44 \\
58\end{array}$ & $\begin{array}{l}58.7 \\
77.3\end{array}$ & $\begin{array}{l}63 \\
63\end{array}$ & $\begin{array}{l}84 \\
84\end{array}$ & \\
\hline \multirow{2}{*}{ Postoperative length of hospital stays } & \multicolumn{2}{|c|}{ Mean \pm SD } & \multicolumn{2}{|c|}{ Mean \pm SD } & \multirow{2}{*}{$<0.001^{* * * *}$} \\
\hline & $3.7 \pm 1$ & & $6.1 \pm 0$ & & \\
\hline
\end{tabular}

Student t-test, Pearson chi square test 
Table (7): Factors affecting stone clearance in all patients.

\begin{tabular}{|c|c|c|c|c|c|}
\hline \multirow{2}{*}{ Factors } & \multirow{2}{*}{\multicolumn{2}{|c|}{$\begin{array}{c}\text { Stone clearance } \\
\text { Mean } \pm \text { SD }\end{array}$}} & \multirow{2}{*}{\multicolumn{2}{|c|}{$\frac{\text { Residual stone }}{\text { Mean } \pm \text { SD }}$}} & \multirow{2}{*}{ P-value } \\
\hline & & & & & \\
\hline Stone burden & \multicolumn{2}{|c|}{$4.7 \pm 1.7$} & \multicolumn{2}{|c|}{$5.2 \pm 2.7$} & $0.188^{\mathrm{N.s}}$ \\
\hline \multirow[b]{2}{*}{ Stag horn stone } & No & $\%$ & No & $\%$ & \multirow[b]{2}{*}{$0.504^{\mathrm{N} . \mathrm{s}}$} \\
\hline & 29 & 19.3 & 14 & 9.3 & \\
\hline Solitary kidney & 9 & 6 & 3 & 2 & $0.770^{\mathrm{N} .}$ \\
\hline $\begin{array}{l}\text { After surgery } \\
\text { Group A } \\
\text { Group B }\end{array}$ & $\begin{array}{l}44 \\
63\end{array}$ & $\begin{array}{c}29.3 \\
42\end{array}$ & $\begin{array}{l}31 \\
12\end{array}$ & $\begin{array}{c}20.7 \\
8\end{array}$ & $0.001^{\text {** }}$ \\
\hline
\end{tabular}

Student t-test, Pearson chi square test

Table (8): Comparison between postoperative complications according to modified Clavien-Dindo grading system between the both groups study.

\begin{tabular}{|c|c|c|c|c|c|}
\hline \multirow[t]{2}{*}{ Complications and its grades } & \multicolumn{2}{|c|}{$\begin{array}{c}\text { PNL } \\
(\text { No }=75)\end{array}$} & \multicolumn{2}{|c|}{$\begin{array}{c}\text { ORSS } \\
(\text { No }=75)\end{array}$} & \multirow[t]{2}{*}{ P-value } \\
\hline & No & $\%$ & No & $\%$ & \\
\hline \multicolumn{5}{|l|}{ Grade I complications } & \multirow{19}{*}{$0.389^{\mathrm{N.s}}$} \\
\hline Hematuria & 1 & 1.3 & 5 & 6.7 & \\
\hline Fever & 5 & 6.7 & 6 & 8 & \\
\hline Wound infection & - & - & 4 & 5.3 & \\
\hline Urine leakage & 4 & 5.3 & 1 & 1.3 & \\
\hline Repeated vomiting & 3 & 4 & 1 & 1.3 & \\
\hline Chest pain and cough & 1 & 1.3 & 1 & 1.3 & \\
\hline Hernia & - & - & 1 & 1.3 & \\
\hline \multicolumn{5}{|l|}{ Grade II complications } & \\
\hline Hematuria (administer blood transfusion) & 8 & 10.7 & 9 & 12 & \\
\hline UTI & 4 & 5.3 & 6 & 8 & \\
\hline Repeated vomiting & 3 & 4 & 2 & 2.7 & \\
\hline Chest pain and cough & 2 & 2.7 & 1 & 1.3 & \\
\hline Fever & - & - & 1 & 1.3 & \\
\hline \multicolumn{5}{|l|}{ Grade III complications } & \\
\hline Pleural injury: (perform intercostal tube) & 3 & 4 & 1 & 1.3 & \\
\hline Hematuria: (perform renal angioembolization) & - & - & 1 & 1.3 & \\
\hline $\begin{array}{l}\text { Obstruction and renal colic due to blood clots (insertion } \\
\text { double J stent) }\end{array}$ & 1 & 1.3 & 1 & 1.3 & \\
\hline Residual stone (required auxiliary maneuver) & 3 & 4 & 1 & 1.3 & \\
\hline
\end{tabular}

Pearson chi-square test 
Table (9): Factors affecting complications rate after surgical management of renal stone in both study group [PNL and ORSS].

\begin{tabular}{|c|c|c|c|c|c|}
\hline Factors & \multirow{2}{*}{\multicolumn{2}{|c|}{$\begin{array}{c}\text { Complication } \\
4.98 \pm 2.5\end{array}$}} & \multirow{2}{*}{\multicolumn{2}{|c|}{$\begin{array}{c}\text { No complication } \\
4.8 \pm 1.8\end{array}$}} & P-value \\
\hline Stone burden $\quad($ Mean \pm SD) & & & & & $0.531^{\mathrm{N} . \mathrm{s}}$ \\
\hline \multirow[b]{2}{*}{$\begin{array}{l}\text { Type of operation } \\
\text { PNL } \\
\text { ORSS }\end{array}$} & No & $\%$ & No & $\%$ & \multirow[b]{2}{*}{$0.389^{\mathrm{N} . \mathrm{s}}$} \\
\hline & $\begin{array}{l}23 \\
28\end{array}$ & $\begin{array}{l}15.3 \\
18.7\end{array}$ & $\begin{array}{l}52 \\
47\end{array}$ & $\begin{array}{l}34.7 \\
31.3\end{array}$ & \\
\hline $\begin{array}{l}\text { Stag horn stone; a large stone that takes up more } \\
\text { than one branch of the collecting system in the } \\
\text { renal pelvis of the kidney. }\end{array}$ & 40 & 26.7 & 67 & 44.7 & $0.168^{\mathrm{N} . \mathrm{s}}$ \\
\hline Solitary kidney & 4 & 2.7 & 8 & 5.3 & $0.959^{\mathrm{N} . \mathrm{s}}$ \\
\hline Recurrent stone & 23 & 15.3 & 41 & 27.3 & $0.666^{\mathrm{N} . \mathrm{s}}$ \\
\hline Preoperative urinary tract infection & 12 & 8 & 22 & 14.7 & $0.856^{\mathrm{N.S}}$ \\
\hline $\begin{array}{lll}\text { Estimated Glomerular } & \text { filtration } & \text { rate } \\
>60 \mathrm{~mL} / \mathrm{min} / 1.73 \mathrm{~m}^{2} & & \\
<60 \mathrm{~mL} / \mathrm{min} / 1.73 \mathrm{~m}^{2} & & \end{array}$ & $\begin{array}{c}42 \\
9\end{array}$ & $\begin{array}{c}28 \\
6\end{array}$ & $\begin{array}{l}79 \\
20\end{array}$ & $\begin{array}{l}52.7 \\
13.3\end{array}$ & $0.707^{\mathrm{N} . \mathrm{s}}$ \\
\hline Medical co-morbidity & 10 & 6.7 & 22 & 14.7 & $0.711^{\mathrm{N} . \mathrm{s}}$ \\
\hline Postoperative double J stent & 25 & 16.7 & 26 & 17.3 & $0.447^{\mathrm{N} . \mathrm{s}}$ \\
\hline $\begin{array}{l}\text { Performance status } \\
\text { I: Normal activity } \\
\text { II: Restricted in physically strenuous activity } \\
\text { III: Less than } 50 \% \text { of daytime in bed } \\
\text { IV: More than } 50 \% \text { of daytime in bed }\end{array}$ & $\begin{array}{c}12 \\
38 \\
1 \\
-\end{array}$ & $\begin{array}{c}8 \\
25.3 \\
0.7 \\
-\end{array}$ & $\begin{array}{c}31 \\
62 \\
3 \\
3\end{array}$ & $\begin{array}{c}20.7 \\
41.3 \\
2 \\
2\end{array}$ & $0.374^{\text {N.s }}$ \\
\hline
\end{tabular}

Student t-test, Pearson chi square test

Table (1): Socio-demographic characteristics of patients included in the study with renal stones treated by PNL and ORSS: The table illustrate that there is no significant statistical difference between the both groups.

Table (2): Medical co-morbidities of among the study groups (PNL and ORSS): The table shows that there is no statistical difference between the both study groups regard the medical co-morbidities.

Table (3): Clinical presentation of the study groups regarding renal stones before treatment by PNL and ORSS: The table shows that there is no significant statistical difference between the both study groups regarding the clinical presentation.

Table (4): Comparison between all groups of patients before treatment and stone criteria: No significant difference was shown regarding the stag horn stone and recurrent stone between the both study groups. While there was a statistically significant difference between the both groups regarding the stone burden.

Table (5): Comparison between the study groups regarding patients` conditions before treatment: The table illustrate that there is no statistical

significant difference regarding patient's condition before treatment among the both groups.

Table (6): Comparison between the both study groups (after surgery and after 3 months follow-up) regarding stone clearance and postoperative hospital stay: There was significant difference stone clearance immediately postoperative and three months after surgery in two groups of patients. There was highly significant difference ( $\mathrm{p}$ - value $<0.001$ ) between postoperative length of hospital stays in all groups of patients [PNL and ORSS].

Table (7): Factors affecting stone clearance: This table shows that there was statistically significant difference between the two groups regarding stone clearance.

Table (8): Comparison between postoperative complications according to modified Clavien-Dindo grading system between the both groups study: No statistically significant difference between the both study groups regarding postoperative complications.

Table (9): Factors affecting complications rate after surgical management of renal stone in both study group [PNL and ORSS]: There was non-statistically significant difference as regarding factors affecting complication in both study groups [PNL and ORSS]

\section{Discussion}

Urinary stone disease is a common and often recurrent condition that can affect kidney function and require a range of medical and surgical treatments. The prevalence of renal stone is 
approximately $2-3 \%$ in the general population (Durgawale et al., 2010).

The results of the present study showed that more than half of patients in both groups were males their age ranged from $35<50$ years old and the majority of them were married and working. In the same line, this result similar to the study reported that renal stone more common in males than females with a mean age of 41years old (Bayar et al., 2014).

The results of the present study showed that diabetes mellitus and hypertension at the time of assessment present with non-significant between PNL and ORSS groups. Other authors report that diabetes mellitus occur in $14 \%$ of patients and hypertension in $30 \%$ of patients under study. (Fathelbab et al., 2013).

In our study, pain was the most frequent clinical presentation affecting of patients having renal stones. Bryant et al. reported that Urinary stones can cause a variety of painful symptoms that typically worsen over time, with a high recurrence rate involving of patients (Bryant et al., 2012).

In our study, the stone burden in ORSS group was larger than that in PNL group due to lack of randomization. In spite of this difference, the initial stone clearance rate was significantly higher in ORSS group. This result similar to the study reported that stone clearance after SWL and PNL less than stone clearance in ORSS (Khalaf et al., 2013). A similar difference in stone clearance of stag-horn stones in favor of ORSS has reported actually, stone burden was not found to be a significant factor that affects stone clearance. However, this difference between stone clearance rates in the two groups was diminished after 3 months because stone clearance was improved spontaneously in PNL group. Thus stone clearance after PNL should not be evaluated finally until every chance for spontaneous passage of residual fragments is exhausted.

In the past, complex stone disease and significantly large stone burden stay indications for ORSS in selected clinical scenarios. It is certainly true that even stag horn stones now be approached effectively and safely with PNL, either alone or in combination with SWL (Dursun et al., 2015). However, ORSS is likely to continue playing important role in the management of this type of stone disease, especially in kidneys with a dilated collecting system (Alkan et al., 2015).

There was no significant difference between complications rate and grades in the two study groups. However, some complications were peculiar to each surgical modalities revealed ORSS complication related to incision as wound infection and hernia, while urine leakage was more in PNL group.
The modified Clavien grading system was used efficiently to evaluate the complications of interventions for renal stones removal (Akilov et al., 2013). So we used it in this study to compare complications of ORSS and PNL. Surprisingly, there was no significant difference in complications rate or grades in both groups. However, some complications were peculiar to ORSS as wound infection and hernia. This is due to lack of considerable incision in PNL. Also, urinary tract infection and postoperative hematuria were more in ORSS group. On the other hand, Urine leakage was more in PNL group. Regarding blood transfusion, there was no difference between both groups. Previous studies on complications of open surgery showed high variability, particularly when comparing endurological and open surgical procedures (Aminsharifi et al., 2016).

Previous studies on complications of surgical intervention for renal stones showed high variability, particularly when comparing endourological and open surgical procedures (Khalaf et al., 2013). Complications after PNLs are not rare and have been reported to occur more of the cases. These are mostly clinically negligible, with minor bleeding or fever often occurring (Yazkan et al., 2013).

There was non-statistically significant difference as regarding factors affecting complication in both study groups [PNL and ORSS]. In my opinion, it's important to assess level of complication for patients after renal stone treatment because these assessments affect positively on patients outcomes and reduce developed complications as cleared in the study, the complications of study groups decreased with following nursing assessment for the grades of complication for patient and factors affecting complications.

It is a fact, study documented that the nurse plays a vital role in care of patients and prevention of infection and others complications in patients with double $\mathrm{J}$ stent and identification of early signs of complications associated with double $\mathbf{J}$ stent such as fever, bladder irritative symptoms. The qualified care nurse must be integrating theoretical knowledge, assessment skills, and problem-solving ability to provide nursing care and maintain high-quality outcomes for patient treated by PNL and ORSS.

\section{Conclusion}

Open renal surgery for large sized stones still has its role in selected cases with stone clearance and complications rates comparable to PNL. 


\section{Recommendations}

- The choice between PNL and open surgery for renal stones should be individualized for each patient.

- Stone clearance after PNL should be assessed 3 months after the procedure.

- Early management of renal stone by PNL or ORSS should be done to minimize postoperative complications.

- It is recommended that similar studies should be replicated on longitudinal bases till one year as a minimum time period for follow-up.

- Replication of the study on a larger probability sample acquired from different geographical areas in Egypt to figure out the main aspects of this problem

\section{Reference}

1. Akilov, F., S. Giyasov, S.T. Mukhtarov, F.R. Nasirov, and J.F. Alidjanov., (2013): Applicability of the Clavien-Dindo grading system for assessing the postoperative complications of endoscopic surgery for nephrolithiasis: a critical review. Turkish journal of urology, 39(3):153.

2. Akman, T., M. Binbay, F. Ozgor, M. Ugurlu, E. Tekinarslan, C. Kezer, R. Aslan, and A.Y. Muslumanoglu., (2012): Comparison of percutaneous nephrolithotomy and retrograde flexible nephrolithotripsy for the management of 2-4 cm stones: a matched- pair analysis. BJU international, 109(9):1384-1389.

3. Alkan, E., A. Saribacak, A.O. Ozkanli, M.M. Başar, O. Acar, and M.D. Balbay., (2015): Retrograde Intrarenal Surgery in Patients Who Previously Underwent Open Renal Stone Surgery. Minimally invasive surgery, 2015:1-5.

4. Aminsharifi, A., D. Irani, M. Masoumi, B. Goshtasbi, A. Aminsharifi, and R. Mohamadian, (2016): The management of large staghorn renal stones by percutaneous versus laparoscopic versus open nephrolithotomy: a comparative analysis of clinical efficacy and functional outcome. Urolithiasis, 1-7.

5. Antonelli, J.A.and M.S. Pearle., (2013): Advances in percutaneous nephrolithotomy. Urologic Clinics of North America, 40(1):99113.

6. Bayar, G., O. Tanriverdi, M. Taskiran, U. Sariogullari, H. Acinikli, E. Abdullayev, K. Horasanli, and C. Miroglu., (2014): "Comparison of laparoscopic and open ureterolithotomy in impacted and very large ureteral stones." Urology journal, 11(2):1423.
7. Bjurlin, M.A., T. O'Grady, R. Kim, M.D. Jordan, S.M. Goble, and C.M. Hollowell., (2012): Is routine postoperative chest radiography needed after percutaneous nephrolithotomy? Urology, 79(4):791-795.

8. Bozkurt, O.F., B. Resorlu, Y. Yildiz, C.E. Can, and A. Unsal., (2011): Retrograde intrarenal surgery versus percutaneous nephrolithotomy in the management of lowerpole renal stones with a diameter of 15 to 20 $\mathrm{mm}$. Journal of Endourology, 25(7):1131-1135.

9. Braticevici, B., Y. Salaheddin, V. Ambert, R. Petca, D. Diaconescu, S. Rascu, and V. Jinga., (2014): Complications of percutaneous nephrolithotomy classified by the modified clavien grading system: a single center's experience over 18 months. Revista Românæ de Urologie nr, 13:18.

10. Bryant, M., J. Angell, H. Tu, M. Goodman, J. Pattaras, and K. Ogan., (2012): Health related quality of life for stone formers. The Journal of urology, 188(2):436-440.

11. Dindo, D., N. Demartines, and P.-A. Clavien., (2004): Classification of surgical complications: a new proposal with evaluation in a cohort of 6336 patients and results of a survey. Annals of surgery, 240(2):205-213.

12. Durgawale, P., A. Shariff, A. Hendre, S. Patil, and A. Sontakke., (2010): Chemical analysis of stones and its significance in urolithiasis. Biomedical Research, 21(3):305-310.

13. Dursun, F., H. Soydan, Ö. Yılmaz, E. Malkoç, F. Ateş, \& T. Şenkul., (2015): Does Previous Open Nephrolithotomy Affect the Success and Complications Rate of Percutaneous Nephrolithotomy? Journal of Urological Surgery, 4:184-187.

14. Fathelbab, T.K., A.A.E. Hamid, \& E. Galal., (2013): Percutaneous nephrolithotripsy under assisted local anaesthesia for high risk patients: Is it effective? African Journal of Urology, 19(4):184-187.

15. Keays, M., L. Guerra, J. Mihill, G. Raju, N. Al-Asheeri, P. Geier, I. Gaboury, M. Matzinger, J. Pike, \& M. Leonard., (2008): Reliability assessment of Society for Fetal Urology ultrasound grading system for hydronephrosis. The Journal of urology, 180(4):1680-1683.

16. Khalaf, I., E. Salih, E. El-Mallah, S. Farghal, \& A. Abdel-Raouf., (2013): The outcome of open renal stone surgery calls for limitation of its use: A single institution experience. African Journal of Urology, 19(2):58-65.

17. Krambeck, A.E. \& J.C. Lieske., (2011): Infection-Related Kidney Stones. Clinical 
Reviews in Bone and Mineral Metabolism, 9(34):218-228.

18. Lee, J.K., B.S. Kim, \& Y.K. Park., (2013): Predictive factors for bleeding during percutaneous nephrolithotomy. Korean journal of urology, 54(7):448-453.

19. Levey, A.S., J. Coresh, T. Greene, J. Marsh, L.A. Stevens, J.W. Kusek, F. Van Lente, and C.K.D.E. Collaboration., (2007): Expressing the Modification of Diet in Renal Disease Study equation for estimating glomerular filtration rate with standardized serum creatinine values. Clinical chemistry, 53(4):766-772.

20. Liu, L.-h., M.-z. Chen, and X. Liang., (2013): The Nursing Care of Patients with Tubeless Percutaneous Nephrolithotomy. Chinese Journal of General Practice, 8:087.

21. Liu Y., L. Jiping., (2011): About B-guided percutaneous nephrolithotomy holmium laser lithotripsy in perioperative nursing. Journal of Clinical Medicine, 1:31.

22. Lu, M.-H., X.-Y. Pu, X. Gao, X.-F. Zhou, J.-G. Qiu, \& J. Si-Tu., (2010): A comparative study of clinical value of single B-mode ultrasound guidance and B-mode combined with color Doppler ultrasound guidance in mini-invasive percutaneous nephrolithotomy to decrease hemorrhagic complications. Urology, 76(4):815820.

23. Matlaga, B.R. \& J.E. Lingeman., (2011): Surgical management of upper urinary tract calculi. Campbell-Walsh Urology, 10th. ed. Philadelphia, PA: Saunders Elsevier.

24. Mousavi-Bahar, S.H., S. Mehrabi, \& M.K. Moslemi., (2011): Percutaneous nephrolithotomy complications in 671 consecutive patients: a single-center experience. Urology journal, 8(4):271.

25. Oken, M.M., R.H. Creech, D.C. Tormey, J. Horton, T.E. Davis, E.T. McFadden, and P.P. Carbone., (1982): Toxicity and response criteria of the Eastern Cooperative Oncology Group. American journal of clinical oncology, 5(6):649656.

26. Rafiei, H., F. Malekpoor, M. Amiri, M. Rahimi Madiseh, \& H. Lalegani., (2014): Kidney stone development among older adults in Iran. Journal of the Indian Academy of Geriatrics, 10:10-13.

27. Rosette, J.d.l., D. Assimos, M. Desai, J. Gutierrez, J. Lingeman, R. Scarpa, \& A. Tefekli., (2011): The clinical research office of the endourological society percutaneous nephrolithotomy global study: indications, complications, and outcomes in 5803 patients. Journal of Endourology, 25(1):11-17.
28. Seitz, C., M. Desai, A. Häcker, O.W. Hakenberg, E. Liatsikos, U. Nagele, \& D. Tolley., (2012): Incidence, prevention, and management of complications following percutaneous nephrolitholapaxy. European urology, 61(1):146-158.

29. Shin, T.S., H.J. Cho, S.-H. Hong, J.Y. Lee, S.W. Kim, \& T.-K. Hwang., (2011): Complications of percutaneous nephrolithotomy classified by the modified Clavien grading system: a single center's experience over 16 years. Korean journal of urology, 52(11):769775.

30. Tang, Y., Z. Feng, \& L. Peng., (2011): Percutaneous nephrolithotomy stone Clinical Nursing. Attend to Practice and Research, 9:26.

31. Turk, C., A. Petrik, K. Sarica, C. Seitz, A. Skolarikos, M. Straub, \& T. Knoll., (2016): EAU Guidelines on Interventional Treatment for Urolithiasis. Eur Urol, 69(3):475-482.

32. Wang, Z., L. Xu, Z. Su, C. Yao, \& Z. Chen., (2014): Invasive management of proximal ureteral calculi during pregnancy. Urology, 83(4):745-749.

33. Yazkan, R., T. Oksay, A. Özorak, İ. Döngel, S.A. Öztürk, \& A. Koşar., (2013): Percutaneous nephrolithotomy: a cause of specific and iatrogenic thoracic complications. Türk Gögüs Kalp Damar Cerrahisi Dergisi, 21(4):987-989. 